\title{
DETERMINATION CONSTANTS OF 4-ELEMENT RHEOLOGICAL MODEL WITH REBOUND RESILIENCE METHOD
}

\author{
Andris Martinovs ${ }^{1}$, Svetlana Polukoshko ${ }^{2}$, Elvijs Apeinans ${ }^{1}$, Edgars Zaicevs ${ }^{1}$ \\ ${ }^{1}$ Rezekne Academy of Technologies, Latvia; ${ }^{2}$ Ventspils University College, Latvia \\ andris.martinovs@rta.lv, pol.svet@inbox.lv, elvijs.apeinans@ rta.lv, edgars.zaicevs@ rta.lv
}

\begin{abstract}
In this paper an express-method and equipment for experimental determination of the 4-element rheological model constants ( 2 elastic modulus, 2 viscosity coefficients) for elastomers are developed. The method is based on rebound of falling hammer against an elastomer material. A mathematical model for describing this collision is elaborated and an algorithm for determination of the constants of the model was developed and realized in Matlab software. Time necessary for determination of the constants is until 5 minutes. It gives an opportunity to significantly accelerate the design and production process of elastomer-metal vibration isolator prototypes with defined parameters of stiffness and damping. The method allows to trace displacement, velocity and acceleration of the metal parts of the shock absorber throughout the collision; this may be realized with Matlab or an analogical program of numerical integration. For forecasting of the mechanical properties of the shock absorber during a long period (considering the aging of elastomer) it is necessary to know the rheological model parameter dependence on time, temperature, energy input and other factors; the proposed method allows to significantly accelerate these experimental studies.
\end{abstract}

Keywords: elastomer, rheological model, elastic modulus, viscosity coefficient, rebound resilience.

\section{Introduction}

Elastomers as products or components are widely used in various industry sectors, such as mechanical engineering, construction, industry of medical equipment, manufacturing of footwear, etc. Elastomers are subjected to static, dynamic and cyclic loading, they dampen shocks and vibrations. Elastomeric product design is associated with a number of specific properties - volume incompressibility, creep, stress relaxation, aging $[1 ; 2]$. Many authors considered in their works the elastomeric product design, for example, calculations of vibroinsulation elements [3; 4], static loadings at small and large deformations [1;2] damping elements in construction [4], calculations of thin-layer elastomer-metal dampers [5; 6], shock damping properties of shoe soles [7], elastomer lifetime forecasting and aging [1;8-10], acoustic absorbers [11], elastomeric actuators for robotic fish [12]. In order to correctly design elastomer products, it is necessary to choose the appropriate model and to know the values of the model constants (physical parameters of materials). As one of the elastomer calculation variants is rheological models $[1 ; 13 ; 14]$. For description of the slow ongoing process (creep, stress relaxation), the 4-element model is considered the best [3]. The given model includes 4 parameters, characterizing the mechanical properties of elastomers -2 modules of elasticity $E_{1}, E_{2}$, and 2 viscosity coefficients $\eta_{2}$ un $\eta_{3}$. The number of elastomer types, available on the market, is huge. Nowadays, elastomers may also be made of two components of liquids, their properties may be modified using a variety of fillers including copper nanoparticles [15], silica nanoparticles [16], recycled raw materials - waste tire particles [11], etc. In addition, the material over time is aging, changing its properties. This means that in each specific case, the material constants will be different. Thus, the best option is to determine the parameters of elastomers experimentally every time. This requires a simple, fast and sufficiently accurate method. In the work [17] the method of determination of constants for 4 elements rheological model using the creep experiment at constant tensile stress and at constant tensile forces is viewed. Unfortunately, the creep experiment requires a significant expenditure of time (at least 2 hours), because there is a need to measure the permanent deformations. The work [13] sets the criteria for the determination of permanent deformations; these deformations are measured within $1 \mathrm{~h}$ after removal of the load. It is technically difficult to maintain a constant tensile stress during the creep test [9], [10]. It is easier to ensure a constant tensile force, but in this case to determine the constants it is necessary to calculate the integral

$$
\int_{t_{1}}^{t_{2}} \varepsilon(t) d t
$$


from experimental curves $\varepsilon=\varepsilon(t)$, where $\varepsilon$ - deformation, $t$ - time. This makes determination of constants more difficult and complicates automation of the measurement process. In this work the creep experiment is replaced by the rebound elasticity test method [18].

The aim of the given work is to develop an express method (algorithm) for experimental determination of constants ( 2 elastic modules, 2 viscosity coefficients) of the 4-element rheological model of elastomeric materials.

\section{Materials and methods}

The constants of the rheological model are experimentally determined for Easy Composites Ltd Xencast PX30 soft flexible polyurethane rubber. The method is also valid for any other elastomer. The samples of material have a cylindrical shape of $40 \mathrm{~mm}$ diameter, $12 \mathrm{~mm}$ height and with mass $15.4 \mathrm{~g}$. The steel disc with mass $m_{2}=51.4 \mathrm{~g}$, diameter $41 \mathrm{~mm}$ and thickness $5 \mathrm{~mm}$ is glued to the front base of a rubber cylinder. Rear base of the cylinder is glued to the side surface of heavy (mass $m_{3}=25 \mathrm{~kg}$ ) parallelepiped. Mass $m_{1}=308 \mathrm{~g}$ (i.e. hammer of pendulum in bearings [18]) at a speed of $v_{0}$ impacts the steel - elastomer shock absorber, which is firmly fixed to the mass $m_{3}$ (Fig. 1,2). It is assumed that $m_{3}>>m_{1}>m_{2}$, the arm $L=200 \mathrm{~mm}$ of the hammer is long, its mass and elastomer mass are negligibly small. As the elastomer layer of the shock absorber brakes the movement of mass $m_{2}$ in the $\mathrm{x}$-axis direction, then after the collision of both bodies $m_{1}$ and $m_{2}$ continue to move together. The speed $v$ of shock absorber plate $m_{2}$ immediately after the collision with the mass $m_{1}$ may be calculated using the momentum conservation law:

$$
v=\frac{v_{0} \cdot m_{1}}{m_{1}+m_{2}} .
$$

This moment of time considered as the beginning; when the time $t=0$ mass $m_{1}$ and $m_{2}$ have the speed $v$, displacement of the front plate $m_{2}$ of the shock absorber $u=0$. For the description of the properties of elastomers the 4-element rheological model is used, which consists of 2 elastic elements with stiffness $c_{1}$ and $c_{2}$ (the elastic modules $E_{1}$ and $E_{2}$ ) and 2 damping elements with coefficients of viscosity $\eta_{2}$ and $\eta_{3}$ [8], [9]. The model is described with a system of equations:

$$
\left\{\begin{array}{l}
\sigma=E_{1} \cdot \varepsilon_{1} \\
\sigma=E_{2} \cdot \varepsilon_{2}+\eta_{2} \cdot \dot{\varepsilon}_{2}, \\
\sigma=\eta_{3} \cdot \dot{\varepsilon}_{3} \\
\varepsilon=\varepsilon_{1}+\varepsilon_{2}+\varepsilon_{3}
\end{array},\right.
$$

where $\sigma-$ mechanical stress applied to elastomer, $\mathrm{Pa}$;

$\varepsilon$ - engineering normal strain of the elastomer layer (total strain);

$\varepsilon_{1}, \varepsilon_{2}, \varepsilon_{3}$ - relative longitudinal deformation (strain) of elements $E_{1}, E_{2}-\eta_{2}$ and $\eta_{3}$.

Assume that at an arbitrary time moment $t$ displacement of mass $m_{2}$ is equal $u$, absolute longitudinal deformation of element $E_{1}$ is $u_{1}$, displacement of parallel connected elements $-E_{2}$ and $\eta_{2}$ is $u_{2}$, of element $\eta_{3}-$ is $u_{3}$. Having regard to the second Newton's law, Hooke's law, definitions of the force of viscosity, stress and relative longitudinal deformation, the following mathematical model for description of the given process is received:

$$
\left\{\begin{array}{l}
\left(m_{1}+m_{2}+m_{e l}\right) \cdot \ddot{u}=-c_{1} \cdot u_{1} \\
\left(m_{1}+m_{2}+m_{e l}\right) \cdot \ddot{u}=-c_{2} \cdot u_{2}-\eta_{2} \cdot \dot{u}_{2} \cdot \frac{S_{0}}{l_{0}} \\
\left(m_{1}+m_{2}+m_{e l}\right) \cdot \ddot{u}=-\eta_{3} \cdot \dot{u}_{3} \cdot \frac{S_{0}}{l_{0}} \\
u=u_{1}+u_{2}+u_{3}
\end{array},\right.
$$

where $S_{0}-$ cross-sectional area of elastomer (perpendicular to the impact load), $\mathrm{m}^{2}$; 
$l_{0}-$ thickness of the elastomer layer at the beginning, $\mathrm{m}$;

$m_{e l}$ - mass of the elastomer layer, $\mathrm{kg}$;

$c_{1}, c_{2}-$ stiffness constants, $\mathrm{N} \cdot \mathrm{m}^{-1}$ :

$$
c_{1}=E_{1} \cdot \frac{S_{0}}{l_{0}}, c_{2}=E_{2} \cdot \frac{S_{0}}{l_{0}} .
$$

The model (3) has 4 equations and 4 unknown functions $u_{1}=u_{1}(t), u_{2}=u_{2}(t), u_{3}=u_{3}(\mathrm{t}), u=u(t)$. Time derivative of the last equation in system (3) gives the relationship between all speeds of elements:

$$
v=v_{1}+v_{2}+v_{3},
$$

where $v=v(t)$ - movement speed in the $\mathrm{x}$-axis direction for the front plate $m_{2}$ of the shock absorber, $\mathrm{m} \cdot \mathrm{s}^{-1}$;

$v_{1}=v_{1}(t)-$ deformation speed of the element $E_{1}$;

$v_{2}=v_{2}(t)-$ deformation speed of the elements $E_{2}$ and $\eta_{2}$;

$v_{3}=v_{3}(t)-$ deformation speed of the element $\eta_{3}$.

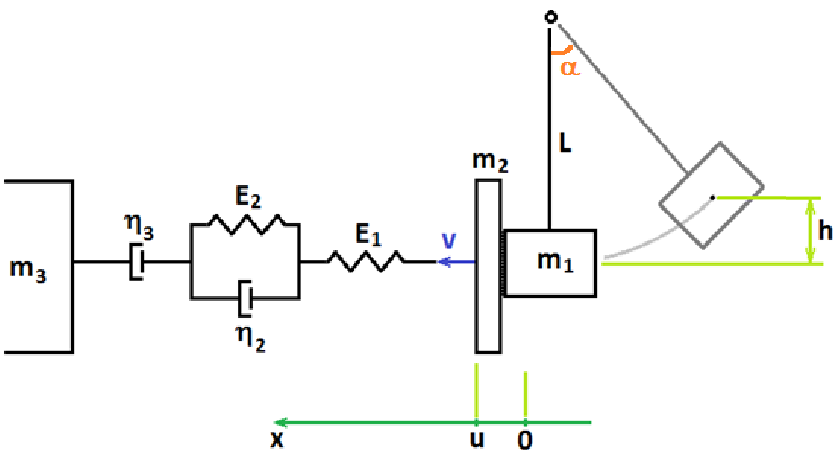

Fig. 1. Calculation model

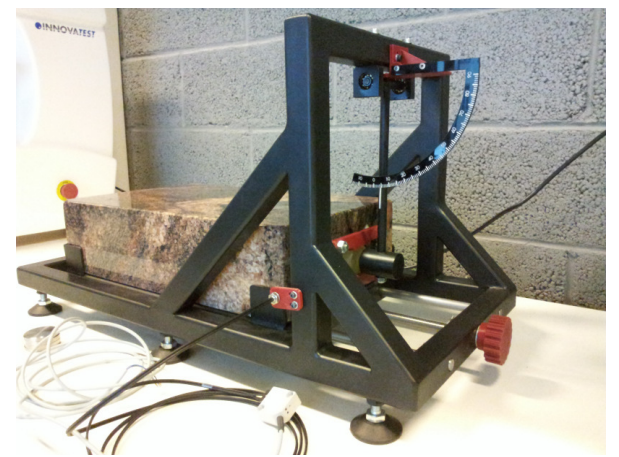

Fig. 2. Schob- pendulum

Solving of equation system (3) is realized numerically by small time steps $\Delta t$, which are numbered consecutively: $i=1,2,3 \ldots$ Derivatives in the system of equations (3) are replaced with forward differences of displacement and speed in the time interval $\Delta t$ :

$$
\left\{\begin{array}{l}
\left(m_{1}+m_{2}+m_{e l}\right) \cdot \frac{\Delta v}{\Delta t}=-E_{1} \cdot \frac{S_{0}}{l_{0}} \cdot u_{1} \\
\left(m_{1}+m_{2}+m_{e l}\right) \cdot \frac{\Delta v}{\Delta t}=-E_{2} \cdot \frac{S_{0}}{l_{0}} \cdot u_{2}-\eta_{2} \cdot \frac{\Delta u_{2}}{\Delta t} \cdot \frac{S_{0}}{l_{0}} \\
\left(m_{1}+m_{2}+m_{e l}\right) \cdot \frac{\Delta v}{\Delta t}=-\eta_{3} \cdot \frac{\Delta u_{3}}{\Delta t} \cdot \frac{S_{0}}{l_{0}}
\end{array}\right.
$$

Initial conditions: if $t=0$ then

$$
\left\{\begin{array}{l}
u=0, \quad v=\frac{v_{0} \cdot m_{1}}{m_{1}+m_{2}} \\
u_{1}=0, \quad v_{1}=v \\
u_{2}=0, \quad v_{2}=0 \\
u_{3}=0, \quad v_{3}=0
\end{array}\right.
$$

After collision the mass $m_{1}$ and $m_{2}$ continues to move along the $x$-axis direction and compresses the elastomer layer of the shock absorber. This kinetic energy is converted into elastic potential energy 
of elastomer deformation (accumulating in elements $E_{1}$ and $E_{2}$ ) and into heat (released in elements $\eta_{2}$ and $\eta_{3}$ ). Mass $m_{1}$ and $m_{2}$ are braked, then they start accelerated motion in the opposite direction of the $x$-axis. In elements $E_{1}$ and $E_{2}$ accumulated elastic potential energy is converted into kinetic energy of mass $m_{1}$ and $m_{2}$ and in heat (released in element $\eta_{2}$ ). At time $t=t^{*}$ elastic deformation of element $E_{1}$ becomes zero, the mass $m_{1}$ has gained the speed $v^{*}$ and separated from the mass $m_{2}$. Then element $E_{1}$ starts to stretch out and begins to brake the mass $m_{2}$. End conditions: if $t=t^{*}$, then

$$
\left\{\begin{array}{l}
u_{1}=0, \\
v=v^{*} .
\end{array}\right.
$$

After the rebound, the mass $m_{1}$ rises at a height $h$. From the principle of conservation of mechanical energy it follows that the mass $m_{1}$ speed immediately after the rebound from the shock absorber is:

$$
v^{*}=\sqrt{2 \cdot g \cdot h},
$$

where $g=9.81 \mathrm{~m} \cdot \mathrm{s}^{-2}$; friction is disregarded.

\section{Results and discussion}

The numerical calculation algorithm includes the following steps.

1. the initial experimental data collection: 4 measurements are carried out - the hammer $m_{1}$ of pendulum falling with 4 different heights $h_{10}, h_{20}, h_{30}, h_{40}$, bounces off from the shock absorber and takes off a height $h_{1}, h_{2}, h_{3}, h_{4}$ (see Fig. 1); experimental values of the speeds $v_{01}, v_{02}, v_{03}, v_{04}$ of the hammer $m_{1}$ are calculated shortly before the collision with the shock absorber and the speeds $v_{\text {exper } 1,}^{*} v_{\text {exper } 2}, v^{*}$ exper $3_{3}, v_{\text {exper } 4}$ immediately after the rebound:

$$
v_{0 j}=\sqrt{2 \cdot g \cdot h_{0 j}}, v_{\exp e r_{-} j}=\sqrt{2 \cdot g \cdot h_{j}},
$$

where $j=1,2,3,4-$ numbers of experimental measurement;

$m_{1}, m_{2}-$ masses are measured;

2. deformation rate $v_{1 j}$ of element $E_{1}$ and the speed $v_{j}$ of the plate $m_{2}$ of the shock absorber at initial moment $(t=0)$ :

$$
v_{1 j}=\frac{v_{0 j} \cdot m_{1}}{m_{1}+m_{2}}, v_{j}=\frac{v_{0 j} \cdot m_{1}}{m_{1}+m_{2}} ;
$$

3. value range (minimum and maximum value) of parameters $E_{1}, E_{2}, \eta_{2}, \eta_{3}$ and the step of changes are defined; in computer program of numerical calculation 4 cycles are created, in which these parameters change ( 4 cycles of one in another). Determination of the parameters $E_{1}, E_{2}, \eta_{2}, \eta_{3}$ is based on 4 experimental measurements with numbers $j=1,2,3,4$, therefore the 5 cycle with variable $j$ is created inside these 4 cycles:

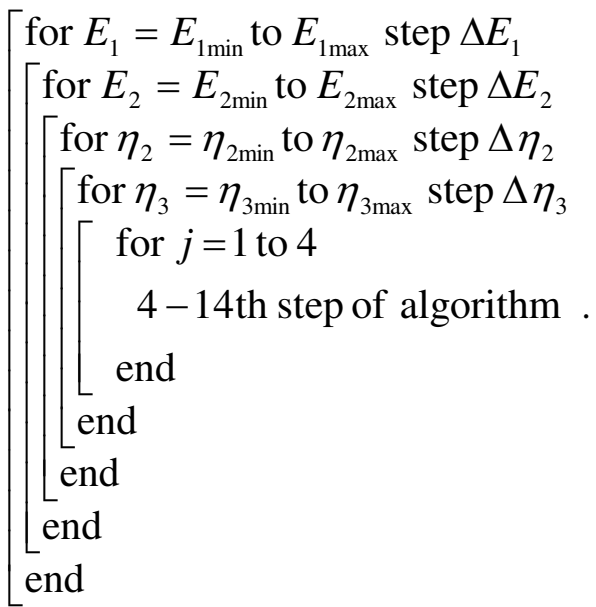


4. deformation change of element $E_{1}$ in time interval $\Delta t$ :

$$
\Delta u_{1}=v_{1} \cdot \Delta t,
$$

where $v_{1}:=v_{1 j}$;

$":=$ " - assignment operator;

5. deformation of element $E_{1}$ at time moment $t$ :

$$
u_{1}:=u_{1}+\Delta u_{1}
$$

6. from the first equation of the system (6) the speed change of the plate $m_{2}$ at time interval $\Delta t$ is obtained:

$$
\Delta v=-\frac{E_{1} \cdot S_{0} \cdot u_{1}}{\left(m_{1}+m_{2}+m_{e l}\right) \cdot l_{0}} \cdot \Delta t
$$

7. $\quad$ speed of the plate $m_{2}$ of the shock absorber at time moment $t$ :

$$
v:=v+\Delta v
$$

8. from the equations system (6) (first and second equation) the deformation of elements $E_{2}$ and $\eta_{2}$ at time moment $t=\Delta t \cdot i$ is obtained:

$$
u_{2 i}=\frac{E_{1} \cdot u_{1}+\frac{\eta_{2}}{\Delta t} \cdot u_{2(i-1)}}{E_{2}+\frac{\eta_{2}}{\Delta t}},
$$

where $i=1,2,3, \ldots-$ number of time interval $\Delta t$;

9. deformation speed of elements $E_{2}$ and $\eta_{2}$ at time moment $t$ :

$$
v_{2}=\frac{u_{2 i}-u_{2(i-1)}}{\Delta t}
$$

10. from the equations system (6) (first and third equation) the deformation of element $\eta_{3}$ is obtained for time moment $t$ :

$$
u_{3 i}=\frac{E_{1} \cdot u_{1}+\frac{\eta_{3}}{\Delta t} \cdot u_{3(i-1)}}{\eta_{3}} \cdot \Delta t
$$

11. deformation speed of element $\eta_{3}$ at time moment $t$ :

$$
v_{3}=\frac{u_{3 i}-u_{3(i-1)}}{\Delta t}
$$

12. deformation speed of element $E_{1}$ at time moment $t$ :

$$
v_{1}=v-v_{2}-v_{3} ;
$$

13. displacement and acceleration of plate $m_{2}$ of the shock absorber at time moment $t$ :

$$
\begin{gathered}
u=u_{1}+u_{2}+u_{3}, \\
a=\frac{\Delta v}{\Delta t} ;
\end{gathered}
$$

14. if $u_{1}>0$ then $t:=t+\Delta t$ and return to step 4 of algorithm;

if $u_{1} \leq 0$ and $j<4$ then end of calculation with the given $j$;

$t_{j}^{*}:=t$ and $v_{j}^{*}:=v$ are assigned values; transition to next $j$ and to step 4 of algorithm; 
if $u_{1} \leq 0$ and $j=4$ then end of calculation with the given $E_{1}, E_{2}, \eta_{2}, \eta_{3}$; assigned values $t_{4} *:=t$ and $v_{4}^{*}:=v$; the root-mean-square deviation (RMSD) between 4 calculated speeds and 4 experimentally obtained speeds after the rebound is determined:

$$
s=\sqrt{\left(v *_{1}-v *_{\exp e r 1}\right)^{2}+\left(v *_{2}-v *_{\exp e r 2}\right)^{2}+\left(v *_{3}-v *_{\exp e r 3}\right)^{2}+\left(v *_{4}-v *_{\exp e r 4}\right)^{2}} ;
$$

if $s<s_{\min }$, then $s_{\min }:=s$ and the values of appropriate parameters $E_{1}, E_{2}, \eta_{2}, \eta_{3}$ are optimal; assigned values $E_{1 \text { opt }}:=E_{1}, E_{2 \text { opt }}:=E_{2}, \eta_{2 \text { opt }}:=\eta_{2}, \eta_{3 \text { opt }}:=\eta_{3}\left(s_{\min }-\right.$ minimal value of RMSD; at the beginning of calculation $s_{\min }:=$ arbitrary large number); go to the next values $E_{1}, E_{2}, \eta_{2}, \eta_{3}$;

15. after execution of all cycles the optimal values of the parameters are determinated: $E_{1 \mathrm{opt}}, E_{2 \mathrm{opt}}$, $\eta_{\text {oppt }}, \eta_{\text {sopt }}$; this is a search result.

The given algorithm is practically implemented in MATLAB program. The experimental data are obtained using Schob - pendulum (Fig. 2) [18]. For Easy Composites Ltd Xencast PX30 soft flexible polyurethane rubber the following values of constants are received: $E_{1}=4.93 \pm 0.24 \mathrm{MPa}$, $E_{2}=0.562 \pm 0.054 \mathrm{MPa}, \eta_{2}=(1.77 \pm 0.073) \cdot 10^{4} \mathrm{~Pa} \cdot \mathrm{s}, \eta_{3}=(6.18 \pm 0.60) \cdot 10^{7} \mathrm{~Pa} \cdot \mathrm{s}$; elastic modulus at static load $E=3.20 \pm 0.10 \mathrm{MPa}$ (obtained by compression test with machine Zwick / Roell Z-150).

In the rebound elasticity test for the given material it is established: if the maximum tilt angle $\alpha$ of Schob pendulum before the collision is $48^{0} \pm 1^{0}$, then after the collision it is $29^{\circ} \pm 0.5^{\circ}$. Using the obtained constants $E_{1}, E_{2}, \eta_{2}, \eta_{3}$ values and the given algorithm, displacement, absolute deformation, speed and acceleration values during the impact were numerically calculated, in Fig. 3-6 the plots of dependence of these values on the time are presented. From the given plots the end moment of collision may be determined; it conforms to the time $t=0.00265 \mathrm{~s}$, absolute deformation is $u_{1}=0, u_{2}=\max$ (maximum value), $u_{3}=\max$, the velocity $v=\max$ and acceleration $a=0$.

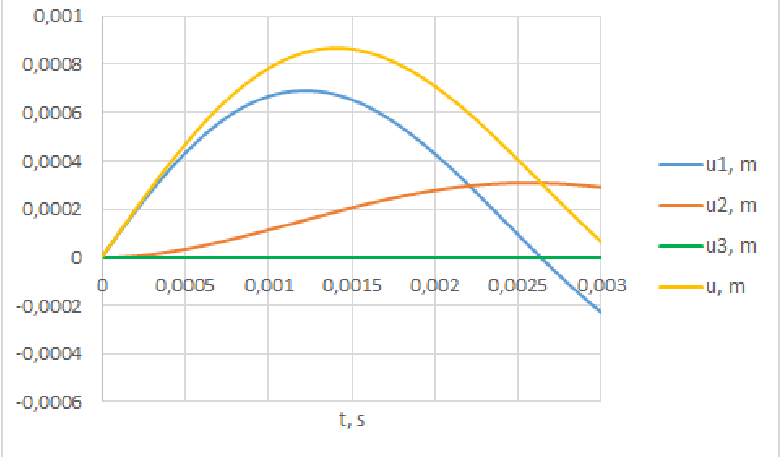

Fig. 3. Displacements $u$ and absolute deformations $u_{1}, u_{2}, u_{3}$ during the impact

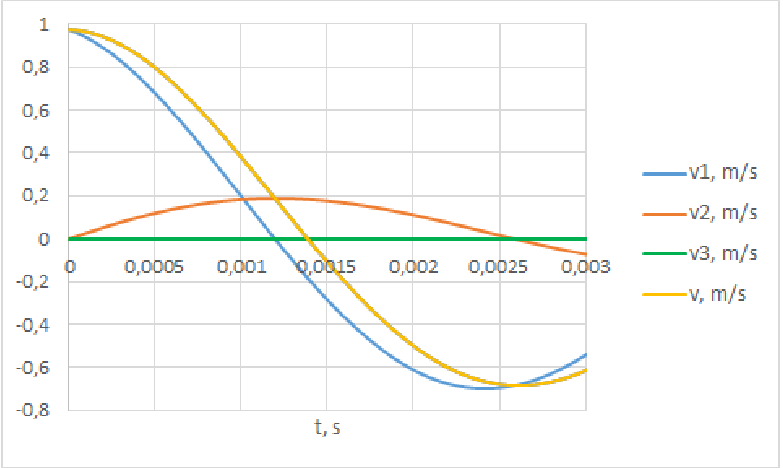

Fig. 5. Deformation speeds $v, v_{1}, v_{2}, v_{3}$ during the impact

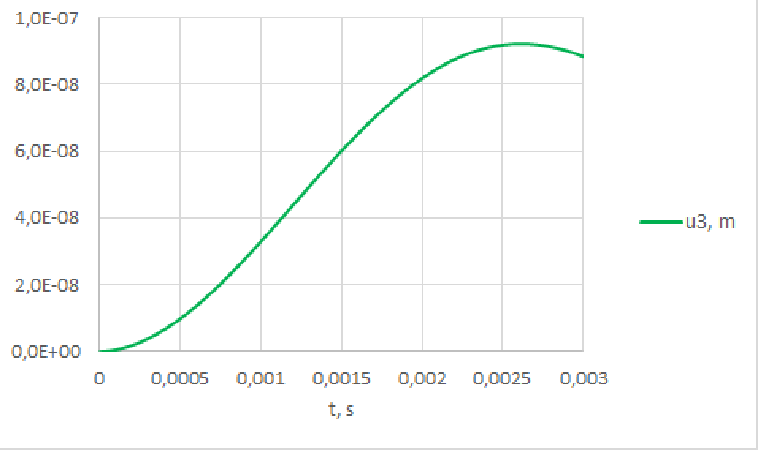

Fig. 4. Absolute deformation $\boldsymbol{u}_{3}$ during the impact

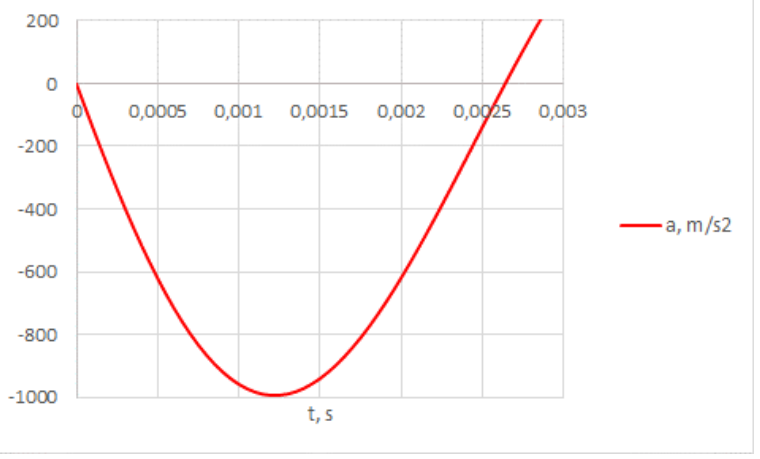

Fig. 6. Acceleration the of plate $m_{2}$ of the shock absorber during the impact 


\section{Conclusions}

1. The proposed method gives the possibility of significantly shortening the time of designing the metal-elastomer dampers with the required stiffness and damping characteristics, because it allows fast (within 5 minutes) definition of the constants $E_{1}, E_{2}, \eta_{2}, \eta_{3}$ of elastomer.

2. The method allows to trace displacement, velocity and acceleration of the metal parts of the shock absorber throughout the collision; this may be realized by numerical integration using Matlab or an analogical program.

3. For forecasting of the mechanical properties of the shock absorber during a long period (considering the aging of elastomer) it is necessary to know the dependence of the rheological model parameters on the time, temperature, energy input and other factors; the given method allows to accelerate significantly these experimental studies.

4. In future investigation it is planned to compare the constants $E_{1}, E_{2}, \eta_{2}, \eta_{3}$ values obtained with help of the proposed method and using the creep test.

\section{References}

1. Лавендел Э.Э. Расчет резинотехнических изделий (Design of Rubber Products). Москва: Машиностроение, 1976, 232 p. (In Russian).

2. Дымников С.И., Лавендел Э.Э., Павловскис А.А.и др. Прикладные методы расчета изделий из высокоэластичных материалов (Applied calculating methods for products from highly elastic materials). Riga: Zinatne, 1980, 238 p. (In Russian).

3. Ляпунов В.Т., Лавендел Э.Э., Шляпочников С.А. Резиновые виброизоляторы (Rubber vibration isolators). Ленинград: Судостроение, 1988, 216 p. (In Russian)

4. Kelly J. M., Konstantinidis D. A. Mechanics of Rubber Bearings for Seismic and Vibration Isolation, UK: John Wiley \& Sons, 2011, 256 p.

5. Gonca V., Polukoshko S., Boyko A. Analytical and Experimental Research of Compressive Stiffness for Laminated Elastomeric Structures. Procedia Engineering, vol. 69, 2014, pp. 1388- 1396.

6. Gonca V., Švabs J., Viba J. Bend with Compression of Thin-Layer Rubber-Metal Elements. Journal of Vibroengineering, 2010, vol. 12, Iss.1, pp. 67-75.

7. Silva R.M., Rodrigues J.L., Pinto V.V., Ferreira M.J., Russo R., Pereira C.M. Evaluation of shock absorption properties of rubber materials regarding footwear applications. Polymer Testing, vol. 28, 2009, pp. 642-647.

8. Губанов В.В. Прогнозирование срока службы резинотехнических изделий, работающих при циклических деформациях (Forecasting the service life of rubber products working under cyclic deformations). Вопросы динамики и прочности, vol. 40, Riga, 1982, pp. 21-33. (In Russian).

9. Губанов В.В., Мурашка Х.И. Долговечность резины при эксплуатации (Durability of rubber during exploitation). Вопросы динамики и прочности, vol. 44, Riga, 1984, pp. 16-21 (In Russian).

10. Губанов В.В. О расчете долговечности резины (Calculation the durability of rubber). Вопросы динамики и прочности, vol. 46, Riga, 1985, pp. 33-36. (In Russian).

11. Soto G., Castro A., Vechiatti N., Iasi F., Armas A., Marcovich N.E., Mosiewicki M.A. Biobased porous acoustical absorbers made from polyurethane and waste tire particles. Polymer Testing, vol. 57, 2017, pp. 42-52.

12. Viba J., Beresnevich V., Tsyfansky S., Kruusmaa M., Fontaine J.G., Megill W. New designs of fin type propulsive devices of robotic fish. 15th International Conference on Advanced Robotics (ICAR), IEEE, June 20-23, 2011.

13. Лейканд М.А., Лавендел Э.Э, Львов С.В., Болотин В.З., Губанов В.В. Приближенная реологическая модель тонкослойного эластомерного подшипника (Approximate rheological model of thin-layer elastomeric bearing). Вопросы динамики и прочности, vol. 36, Riga, 1980, pp. 157-168. (In Russian).

14. Euler M., Bieghold H.-A. Ermittlung von Kriechfunktionen für das viskoelastische Materialverhalten von Holz im Zugversuch. LACER No.4, Universität Leipzig, 1999, pp. 319-334. 
15. Hadi Najafi Pazhooh, Rouhollah Bagheri, Ali Adloo. Fabrication of semi-conductive natural rubber nanocomposites with low copper nanoparticle contents. Polymer, vol. 108, 2017, pp. 135-145.

16. David Le Strat, Florent Dalmas, Solo Randriamahefa, Jacques Jestin, Véronique Wintgens. Mechanical reinforcement in model elastomer nanocomposites with tuned microstructure and interactions. Polymer, vol. 54, 2013, pp. 1466-1479.

17. Martinovs A. Gumijas reologiskā modeļa parametru noteikšana (Parameter determination for the reological model of rubber). RTU Zinātniskie raksti, 6.sērija, "Mašīnzinātne un transports. Mehānika”, vol. 7, 2002, pp. 65-70. (In Latvian).

18. DIN 53512-2000, ISO 4662 standard „Bestimmung der Rückprall- Elastizität (Schob- Pendel). Determining the rebound resilience of rubber using the Schob pendulum". 